\title{
DID TECHNOLOGY IMPROVE SAFETY? AN EMPIRICAL STUDY OF CONTROLLED FLIGHT
}

\section{INTO TERRAIN ACCIDENTS}

Alex Y. L. Lu ${ }^{1}$

Dept. of Air Transportation, Kainan University, Taoyuan, Taiwan

Cheng-Hua Yang ${ }^{2}$

Dept. of Airline and Transport Service Management, National Kaohsiung University of Hospitality and Tourism, Kaohsiung, Taiwan

\begin{abstract}
Aviation safety has been affected greatly by technological improvements. A series of Ground Proximity Warning Systems (GPWSs) were developed to prevent accidents during Controlled Flight into Terrain (CFIT). This study analyzed the role of GPWS (or Enhanced GPWS, EGPWS) in flight safety history to determine how effective GPWS/EGPWS was in terms of preventing CFIT. The result showed a substantial increase in CFIT accidents due to the rapid growth of aviation development. This situation improved after the mandatory installation of GPWSs in commercial aircraft. However, the legal requirement did not apply to all general aviation. Most CFIT accidents have involved general aviation aircraft that do not have GPWS/EGPWS installed on board. Thus, the mandatory requirement should apply to all civil aircraft. CFIT accidents have also been reduced considerably in developed countries whereas they remain a major issue in developing countries.
\end{abstract}

Keywords: Aviation Safety, Controlled Flight into Terrain, Ground Proximity Warning System.

${ }^{1}$ Alex Y.L. Lu is an Assistant professor, Dept. of Air Transportation, Kainan University, Taoyuan, Taiwan.

${ }^{2}$ Cheng-Hua Yang is an Associate professor, Dept. of Airline and Transport Service Management, National Kaohsiung University of Hospitality and Tourism, Kaohsiung, Taiwan. E-mail address: edwardyang0920@gmail.com (Corresponding Author) 


\section{INTRODUCTION}

According to the Boeing's statistics shown in Figure 1, flight hours and departures have risen continuously throughout the development of aviation industry (Boeing, 2012). Hours flown doubled in the 20 years between 1992 and 2011, while the departures increased by almost three quarters. The correlation between the aviation accident rate and the evolution of technological development in the past 60 years shows that the global accident rate has improved significantly, which is attributable mostly to improved technology (Mathews, 2004).

Figure 1: Annual Departures and Flight Hours (Boeing, 2012)

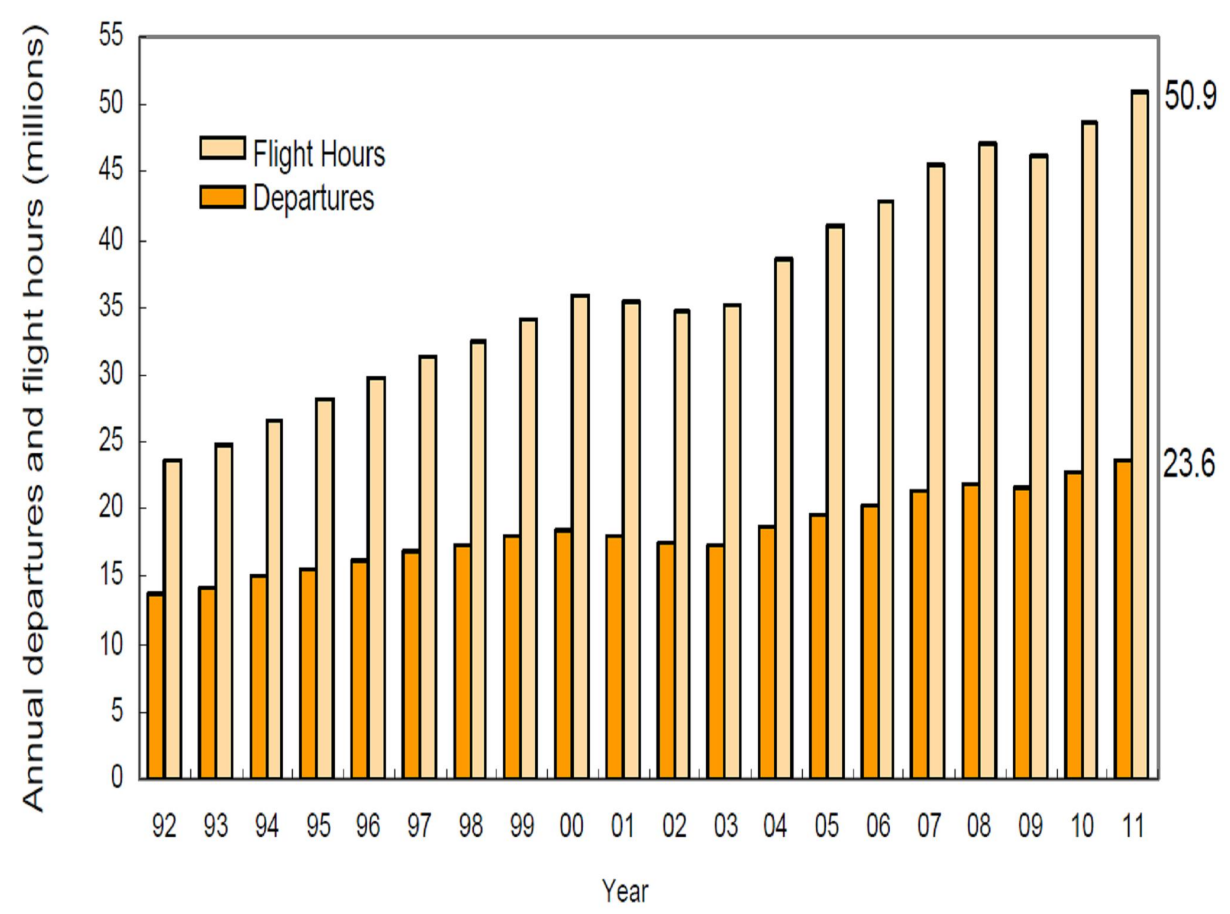

Given the ever-changing nature of aviation technology and automated systems, many types of aircraft accident preventive warning systems have been developed, such as ground proximity warning systems and traffic collision avoidance systems (TCAS). Since the introduction of these systems, regulations have been enacted in recent years to enforce the installation of various systems.

This study analyzed Controlled Flight into Terrain (CFIT) accident data for the past 30 years, to determine the correlation between the introduction of Ground Proximity Warning Systems (GPWSs), 
the number of accidents, and the death toll, by reviewing the death toll per unit flight. Thus, this study analyzed the general trend of current CFIT accidents and verified the improvement since the enactment of a regulation that mandated GPWS installation.

\section{LITERATURE REVIEW}

\subsection{The Effects of New Systems on Pilots}

Avionics systems comprise communications, navigation, and display management, and aircraft navigation systems have undergone great change in the past three decades. In early $1970 \mathrm{~s}$, the aircraft instruments, fuel systems, radios, radar, engine control, and radio navigation were mostly individual electromechanical systems. After the 1970s, the cockpit was equipped with various artificial warning devices, such as GPWS, to more easily determine whether the system was working properly. When an aircraft approaches terrain in an abnormal manner, the GPWS will alert the pilot with warnings based on voice, light, and the screen displays (Baxter \& Ritter, 1999).

Nowadays, civil aircraft are highly reliant on computer automation, because more and more people are taking flights and air traffic is increasingly complicated, which makes flight safety an issue of concern (Orlady \& Orlady, 1999). Sanfourche (2001) pointed out that in a convergence era where new aviation technology systems are replacing the old ones, pilots face challenges when adapting to the new systems, which differ tremendously from the old ones. For example, when the A320 was launched in 1988, its cockpit control system no longer followed the old-fashioned fly by cable operation and instead its systems were fly-by-wire. Computer automated systems such as the Flight Management System (FMS) have a significant role in cockpit and they have made a major contribution to flight safety.

Rudisill (1995) pointed out that the advent of navigation system aimed to relieve the pilot's workload, but this was not the case because the workload has been transferred to other areas. A pilot's main 
job is to operate the aircraft during takeoff and landing, to monitor system functioning, to manage the FMS equipment, and to make decisions.

However, pilots need to spend more time understanding and managing the operation of new systems and the meaning of the screen displays, rather than simply focusing on their missions. The advent of navigation systems requires that pilots learn how to fly and communicate during their training course, but they also need to learn how to interpret the computer data to avoid perception gaps during data interpretation.

\subsection{Cognitive Gap between Computer Systems and Pilot Perception}

Moray (1987) pointed out that computer automated systems may help pilots gain flight experiences, and when pilots use the systems, but they need to check the computer systems to analyze and verify that the information provided by the systems conforms to the current situation. Baxter and Ritter(1999) showed that, in critical situations, the information provided by the computer systems may not be correct because they are designed by humans who may feed all possible causes of accidents into the computer systems, but they may not be able to include unknowns so pilots should not be over-reliant on the information provided by their computer systems.

During aviation operation, a cognitive gap may occur between the pilot and the computer system when the computer system lacks clear instructions so the pilot is unable to interpret its behaviour. Sherry et al. (2002) proposed four theoretical types of cognitive inconsistency. The first two types are real errors and recognition errors. Real errors occur when the information displayed by the computer system is inconsistent with the reality of the situation. The system cannot detect dangerous conditions, which means that the computer system itself has problems. Recognition errors occur when the computer system detects a dangerous condition during flight, but the pilot checks and finds that it is a problem with the computer system and the aircraft is actually in a safe state so the pilot decides that the information provided by the computer system is incorrect. The 
other two error types are detecting the presence and absence of an error message, i.e., when the system detects an error message and the message is true, it can help the pilot make an amendment whereas if the system does not detect any error, but the flight is actually in a dangerous situation, the pilot may believe that the aircraft is in a safe condition.

The pilot should always pay attention to whether the computer system is consistent with the real situation. If not, the pilot should be able to decide instantly if the computer system is in error and immediately take follow-up steps to correct the problem. Computer systems are designed and developed by humans so the information is unlikely to be $100 \%$ correct, which could sometimes mislead the pilot into making an incorrect judgment.

\subsection{The Features and Effects of Warning Systems}

Warning systems have been developed to prevent aircraft accidents and maintain flight safety. Over the past decade, the aviation industry has developed various warning systems such as GPWS, TCAS, the predictive wind shear system, and system failure warning mechanism.

According to Amy et al. (2002), the new generation of aircraft warning systems has communication functions but constant tests and operation effect evaluations are required due to the rapid release of these new features. Billings (1997) also argued that when an aircraft experiences an emergency, this may affect the pilot's task performance and if the pilot is not fully familiar with the operation of the automation system, it may force the pilot to transfer their attention to the computer system, which increases the workload of the pilot. As a result, the avoidance of such situations should be considered in the system design.

In a strict warning system, over-rigorous standards may also result in excessive pilot distraction and possible decision errors. Hasse (1992) and Dingus et al. (1997) recognized that the pilot may often be misled by unnecessary warning messages in safe conditions, which could result in the pilot's 
gradual distrust of the system. Moreover, if the warning system always has intense reaction whenever a problem occurs, unnecessary warning may be regarded as a potential risk. For example, the early GPWSs had many errors and unnecessary warnings.

A warning system is expected to convey an alarm only in exceptional circumstances. Riley pointed out that if pilots do not understand the characteristics of the warning system, the pilot may mistakenly believe a critical situation occurs whenever the system signals a warning. The pilot's trust in the warning system may vary in different conditions. If the information provided by the warning system is correct, but the pilot does not comply with the instructions, or the information is incorrect and the pilot executes the instructions accordingly, this reflects whether the pilot trusts the system or not. Today, many fields such as aviation, rail, marine, medicine, and agriculture have to face the issue of whether they trust their warning system. Riley (1996) also noted that a few studies have shown that, when using a computer system, the pilot will compare their personal experiences learned during crisis handling with the information from the warning system and, in case of an emergency, the pilot will use familiar methods to deal with the crisis.

Mosier et al. (1999) suggested that the two major consequences of a pilot's excessive reliance on the warning system are reduced alertness during crises and lowered attention to the monitor screen. Elvers and Erif (1997) suggested that simplified information might be helpful for the pilot. This has been supported by several studies using different approaches, which are widely used in laboratory experiments, to depict the pilot's task execution, and they have shown that simplification does help. However, in exceptional circumstances, the pilot may not know how to operate in the moment and they may need more information to identify the situation before making decisions about the next step. Therefore, imagining the occurrence of emergency conditions and simulate how the system would react to a crisis are the most important considerations in the system design.

Parasurman and Riley (1997) noted that while the correct warning can help the pilot to complete the 
flight, an erroneous one can also cause a disaster. Warning systems have been designed and developed based on the findings from past accidents so all the factors related to accidents can be incorporated into the system and the pilot can be warned accordingly when similar situations occur. To some extent, simply including all of the factors related to past accidents in the system may be too conservative, because even if the alarm is legitimate because not all emergencies will have the same background.

Vandor (1999) suggested that the scope of aviation regulations is vast so when a risk occurs, the messages provided by different warning systems in various circumstances may affect the pilot's response indirectly.

\subsection{Outline of CFIT}

In the late 1960s, a series of Controlled Flight into Terrain (CFIT) accidents took the lives of hundreds of people. A CFIT accident occurs when a correctly functioning airplane under the control of a fully qualified and certificated crew is flown into terrain (or water or obstacles) with no apparent awareness on the part of the crew. Since the early 1970s, a number of studies looked at the occurrence of CFIT accidents. The findings from these studies indicated that many of the accidents could have been avoided if a warning device known as GPWS had been installed. As a result of these studies and recommendations from the U.S. National Transportation Safety Board (NTSB), the FAA required all large turbine and turbojet airplanes to install TSO-approved GPWS equipment from 1974. In March 2000, the U.S. FAA amended the operating rules to require that all U.S. registered turbine-powered airplanes with six or more passenger seats (excluding the pilot and copilot seating) be equipped with an FAA-approved TAWS (FAA, 2000).

A GPWS is a system designed to alert pilots if their aircraft is in immediate danger of flying into the ground or an obstacle. The U.S. FAA (2000) defines a GPWS as a type of terrain awareness warning system (TAWS). More advanced systems introduced in 1996, are known as enhanced ground 
proximity warning systems (EGPWS), although they are sometimes confusingly known as terrain awareness warning system (TAWS). According to the Flightglobal website, Learmount (2009) pointed that none of the accidents that occurred before 2005 involved commercial or civilian jets with jet engine or turbo propeller, installed with TAWS, which is clear evidence that TAWS can effectively reduce the occurrence of CFIT events. At present, only $5 \%$ of business jetliners are not installed with EGPWS. In the 10 years since 1997, the decline of CFIT accidents had been obvious, but the reduction is still slow. After 2004, the number of CFIT accidents involving commercial jets continued to decline.

According to the $9^{\text {th }}$ edition ICAO Annex 6 , a GPWS should provide an automatic timely and distinctive warning to the flight crew when the airplane is in potentially hazardous proximity to the earth's surface. A GPWS shall also provide, unless otherwise specified, warnings of the following circumstances:

(1) excessive descent rate;

(2) excessive terrain closure rate;

(3) excessive altitude loss after takeoff or turning;

(4) unsafe terrain clearance while not in a landing configuration:

(a) gear not locked down;

(b) flaps not in a landing position; and

(5) excessive descent below the instrument glide path.

The latest standard regarding aircrafts that are required to be equipped with GPWS, the International Civil Aviation Organization (ICAO) Annex 6, stipulates several standards, as shown as Table 1 (ICAO, 2010).

In the United States of America, the FAA (2000) requires that all its aircraft capable of carrying more than six (inclusive) passengers, under the governance of Part 121, Part 91, Part 135, Part 125, and 
Part 129, should be installed with EGPWS and that all new aircraft produced after March 2002 should also be installed with EGPWS. All aircrafts already in service with the above specifications or under the same governance, should finish conversion with the EGPWS add-ons by March 2005. These measures demonstrate the necessity for EGPWS installation to avoid CFIT accidents.

Table 1: List of Aircraft that are Required to be Equipped With a GPWS

\begin{tabular}{|c|c|c|c|c|c|}
\hline Class & $\begin{array}{l}\text { Engine } \\
\text { Type }\end{array}$ & MTOW & PAXs & Mandated & Remark \\
\hline \multirow{6}{*}{$\mathrm{CAT}^{\mathrm{a}}$} & \multirow{5}{*}{ turbine } & $>15,000 \mathrm{~kg}$ & $>30$ PAXs & EGPWS/TAWS & \\
\hline & & $>5,700 \mathrm{~kg}$ & $>9$ PAXs & GPWS & \\
\hline & & $>5,700 \mathrm{~kg}$ & $>9$ PAXs & EGPWS/TAWS & $\begin{array}{l}\text { certificate } \\
\text { airworthiness first } \\
\text { issued on or after } \\
\text { January } 1,2004\end{array}$ \\
\hline & & $>5,700 \mathrm{~kg}$ & $>9$ PAXs & EGPWS/TAWS & $\begin{array}{l}\text { From January 1, } \\
2007\end{array}$ \\
\hline & & $\leq 5,700 \mathrm{~kg}$ & $\leq 9$ PAXs & \multirow[b]{2}{*}{$\begin{array}{l}\text { GPWS that provides } \\
\text { warnings of the descent rate } \\
\text { and altitude loss after } \\
\text { takeoff or turning, warnings } \\
\text { of unsafe terrain clearance, } \\
\text { and a forward-looking } \\
\text { terrain avoidance function. }\end{array}$} & Recommendation \\
\hline & piston & $>5,700 \mathrm{~kg}$ & $>9$ PAXs & & $\begin{array}{l}\text { From January 1, } \\
2007\end{array}$ \\
\hline \multirow{3}{*}{$\mathrm{GA}^{\mathrm{b}}$} & \multirow{2}{*}{ turbine } & $>5,700 \mathrm{~kg}$ & $>9$ PAXs & EGPWS/TAWS & \\
\hline & & $\leq 5,700 \mathrm{~kg}$ & $\leq 9$ PAXs & EGPWS/TAWS & Recommendation \\
\hline & piston & $>5,700 \mathrm{~kg}$ & $>9$ PAXs & EGPWS/TAWS & Recommendation \\
\hline
\end{tabular}

Notes:

CAT = Commercial Air Transport; GA = General Aviation; PAX = Passenger

Summarized by authors

EGPWS is an enhanced version of the original GPWS, which has a wider terrain database that gives pilots more time to react. However, the EGPWS database is constructed from multiple data sources. GPWS uses complex algorithms whereas EGPWS is simplified, and this inconsistency may make the pilot unable to understand the information provided by EGPWS during the flight, thereby requiring the pilot to spend more time interpreting the messages. The original intention of creating the new 
system was to help the pilot but the result may be quite the opposite because it makes the already complicated data even more intricate (Mosier \& Skitka, 1999).

\section{RESEARCH TOPICS AND METHOD}

This study investigated the time distribution of CFIT accidents after the enforcement of GPWS installation. The current ICAO standards and regulations for GPWS/EGPWS enforcement enacted in various countries were considered and the research focused on accidents during controlled flight that involved crashing into water, ground level, or hills/mountains.

The Aviation Safety Network (ASN) is an exclusive service of the Flight Safety Foundation (FSF), most of the information contained in the ASN site is based on information from official sources (authorities and safety boards). Based on the ASN databases, investigation reports for all accidents related to controlled flights crashing into water, level ground, and hills/mountains during the 30 years from 1979 to 2011 were collected and compiled in this study. Given that the investigations of most aviation accidents take more than one or two years, this study considered the CFIT accident statistical period from 1979 to 2011.

A GPWS is a system designed to alert pilots if their aircraft is in immediate danger of flying into the ground or water, while more advanced systems such as EGPWS/TAWS have a forward-looking terrain avoidance function that can prevent the airplane from flying into ground, water, hills, and mountains. Therefore, this study determined various detailed parameters, as follows:

(1) the accident rates for each CFIT type in each year (i.e., crashing into water, level ground, and hills/mountains);

(2) the death toll for each CFIT type in each year;

(3) the airplane type involved in each accident (i.e., turbine-engined or piston-engined airplanes);

(4) the airplane category in each accident (i.e., the maximum certificated takeoff mass and/or 
the number of authorized passengers);

(5) the location of each accident;

(6) other available considerations.

This study defined the death toll per unit flight as the test parameters to examine whether the legal requirements for GPWS installations on aircraft with a capacity over a specific number of passengers had the expected result. This study has analyzed the history of accidents to provide insights for further discussion. Geographical factors by countries were added to study CFIT-related issues and to explore the evolution of the accidents after technological advancement, and to examine whether the flight safety was improved as expected. Finally, our conclusions and recommendations are presented. The research flow is shown in Figure 2.

Figure 2: Research Flow Chart

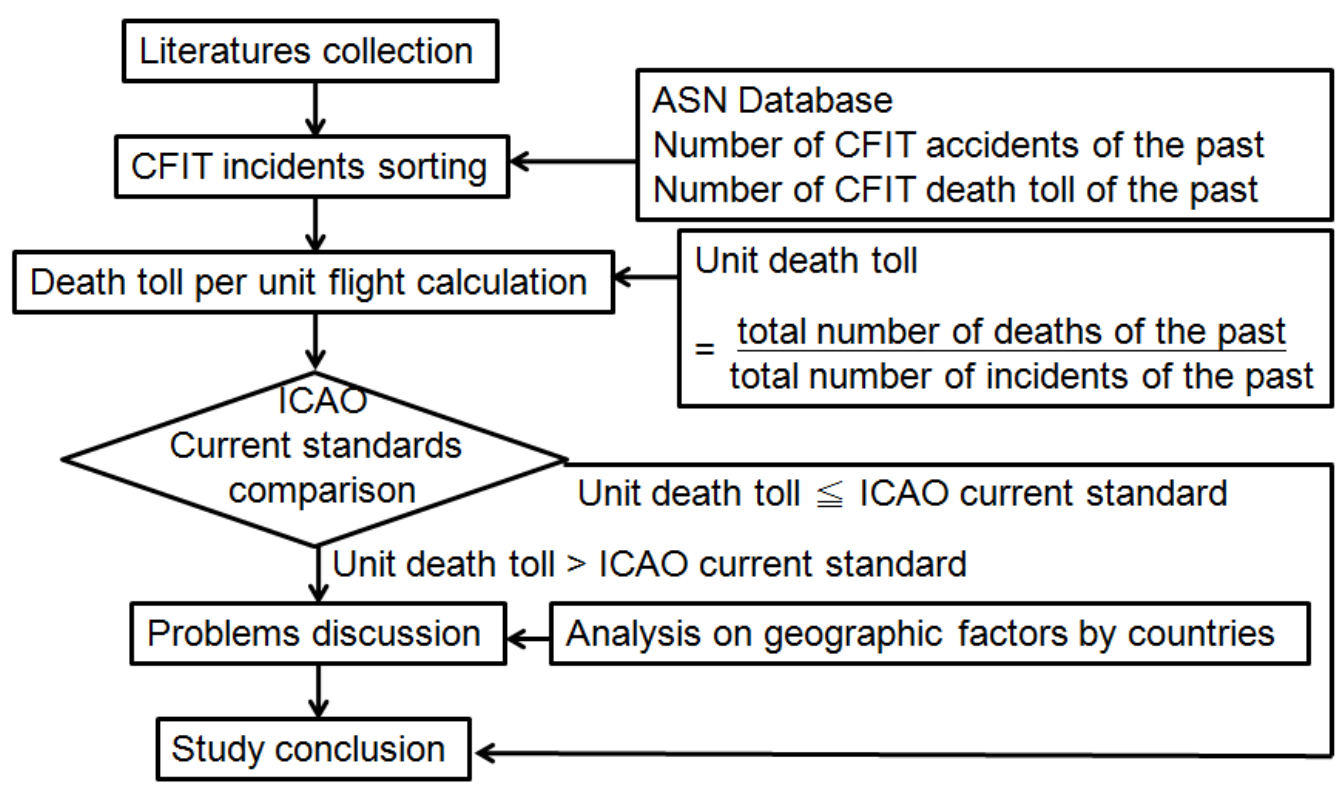

\section{DISCUSSION}

\subsection{Analysis of the Annual Trends of CFIT Accidents}

Figure 3 shows the number of CFIT accidents yearly from 1979 to 2011 and the five-year average trend (the purple line indicates the general trend). The CFIT accidents were subdivided further into 
CFIT-Hill/Mountain (green line), CFIT-Level Ground (brown line), and CFIT-Water (blue line). CFIT-Hill/Mountain and CFIT-Level Ground accidents engaged the majority of these accidents. CFIT-Hill/Mountain accidents were the most frequent, followed by CFIT-Level Ground and CFIT-Water. As to CFIT-Hill/Mountain and CFIT-Level Ground, the evolution of the trends was similar, while the overall CFIT trend also varies in tune with the distributions of these two categories. By contrast, CFIT-Water remained relatively low with around one accident each year.

The overall trend in the last 30 years indicates that the number of CFIT accidents before 1995 averaged less than 10 accidents per year while 15 accidents in 1982 and 24 accidents in 1989 reached their peaks. In general, the change in the trend before 1995 was not obvious. From 1995 to 2006, an increase in CFIT accidents was apparent, where the accident frequency was the highest and almost twice the average during 1979 to 1995 . However, the mandated installation of GPWS in aircraft after 2007 reduced the overall accidents significantly. After 2001, the number of CFIT-Level Ground accidents stabilized and began to decline gradually each year, whereas the number of CFIT-Hill/Mountain accidents did not decrease until after 2007. This phenomenon manifested the function of the installation of GPWS.

In March 2002, the FAA demanded that U.S.-registered airplanes, manufactured after March 29, 2002, must be equipped with TAWS. Thus, aircraft produced before 2002 were not necessarily equipped with GPWS; therefore, the CFIT accidents in 2002 continued to increase. The decline occurred in 2006 after the regulations enforced by ICAO on January 1, 2003 and regulations enforced by FAA in March 2005, which required that all turbine-powered airplanes manufactured on or before March 29, 2002 must be equipped with TAWS, as well as the mandates of many other countries in 2005 that claimed add-on TAWS. Thus, the effect of GPWS installation was evident after 2006. The Boeing statistics on traffic growth indicate that the flight hours and the business of the aviation industry have doubled in the past 20 years, which agrees with the 10 accidents in 1990 and 18 in 2006. Accordingly, there was a close correlation between the increase in the flight hours, the 
overall traffic, and the annual increase in CFIT accidents.

Figure 3: Annual CFIT Accidents and the Five-Year Average

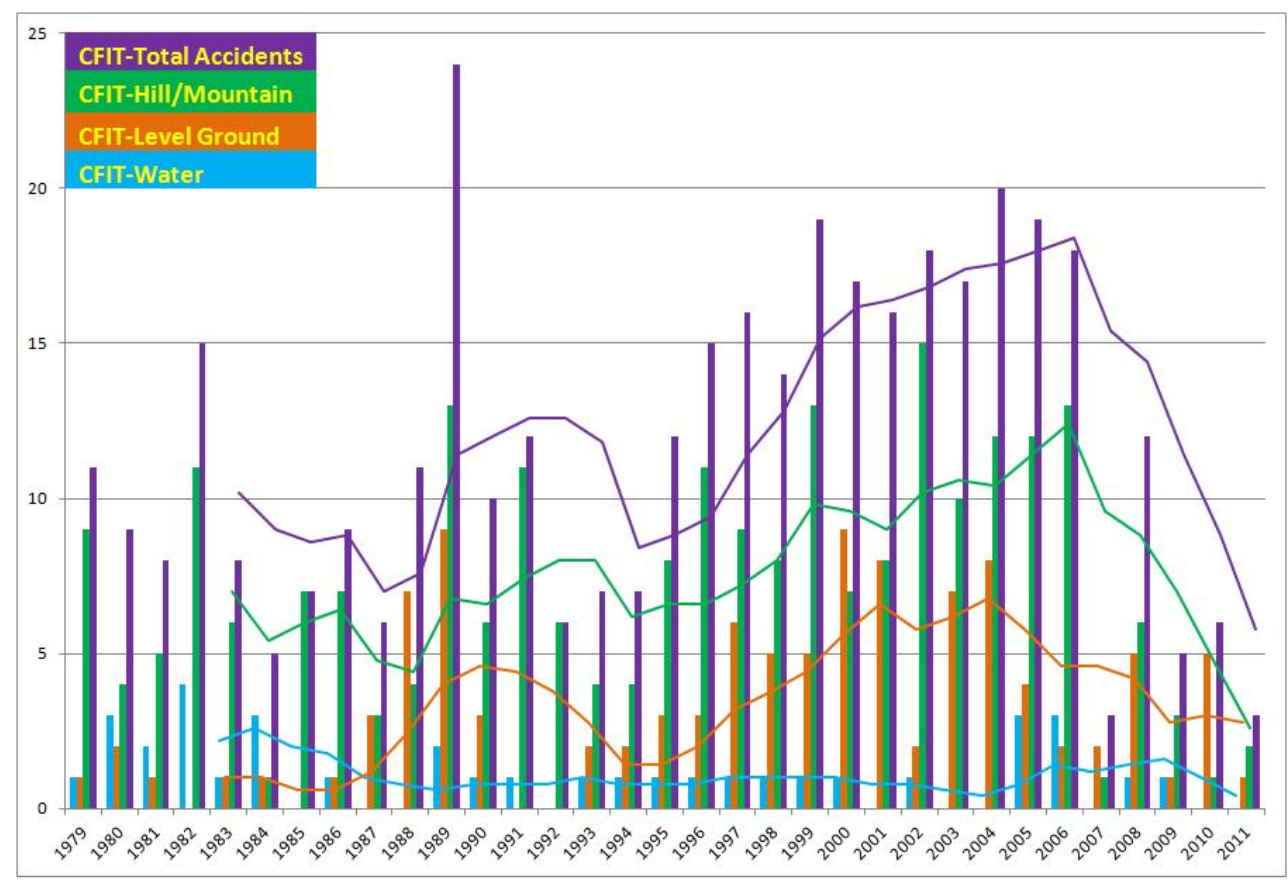

Figure 4 shows the annual CFIT accident trend for aircraft with Maximum Takeoff Weight (MTOW) more than $5,700 \mathrm{~kg}$ or a capacity of more than 9 passengers. This figure shows CFIT-Hill/Mountain had the largest number of accidents, followed by CFIT-Level Ground. These two have similar trends but CFIT-Water remains different from about one accident each year from 1988, which has not changed with the increased air traffic volume. Figure 4 also shows that the numbers of CFIT-Level Ground accidents in 1988 and 1989 were greater than the average number of accidents in the same years, whereas CFIT-Hill/Mountain maintained a fluctuating but generally steady trend. Since 1994, CFIT-Hill/Mountain and CFIT-Level Ground have increased, with similar growth slopes. However, CFIT-Level Ground started to decline in 2002, whereas CFIT-Hill/Mountain did not fall until 2006. The CFIT frequencies agree with the installation of GPWS functions.

Figure 5 illustrates our analysis of the situation for large aircraft with a maximum take-off weight of more than $15,000 \mathrm{~kg}$ or a capacity of more than 30 passengers, which determined a significantly different trend for CFIT-Level Ground accidents, compared with CFIT-Hill/Mountain accidents. 
Figure 4: Annual CFIT Accidents involving Aircrafts with a Maximum Takeoff Weight of More than 5,700 Kg or 9 Passengers and the Five-Year Average

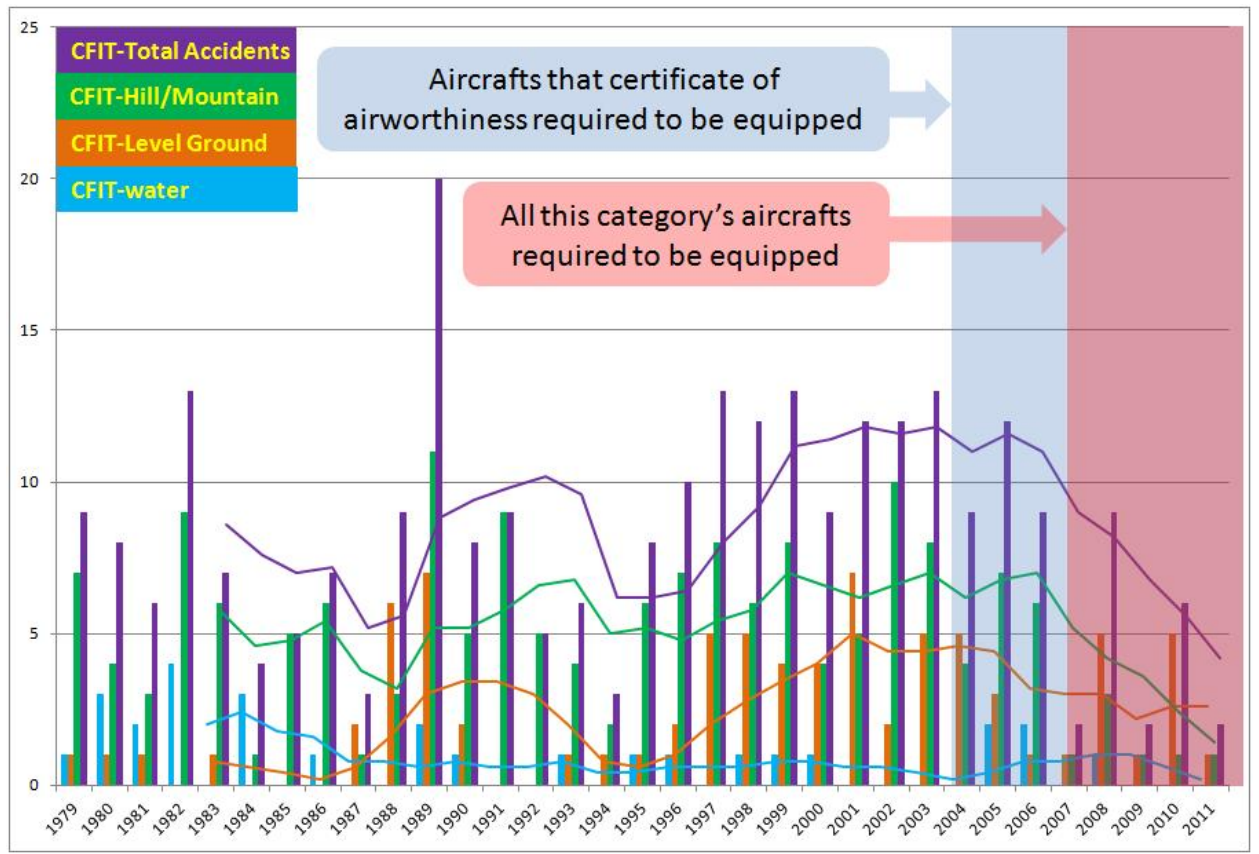

Figure 5: Annual CFIT Accidents Involving Aircrafts with a Maximum Takeoff Weight of More Than 15,000 Kg or 30 Passengers and the Five-Year Average

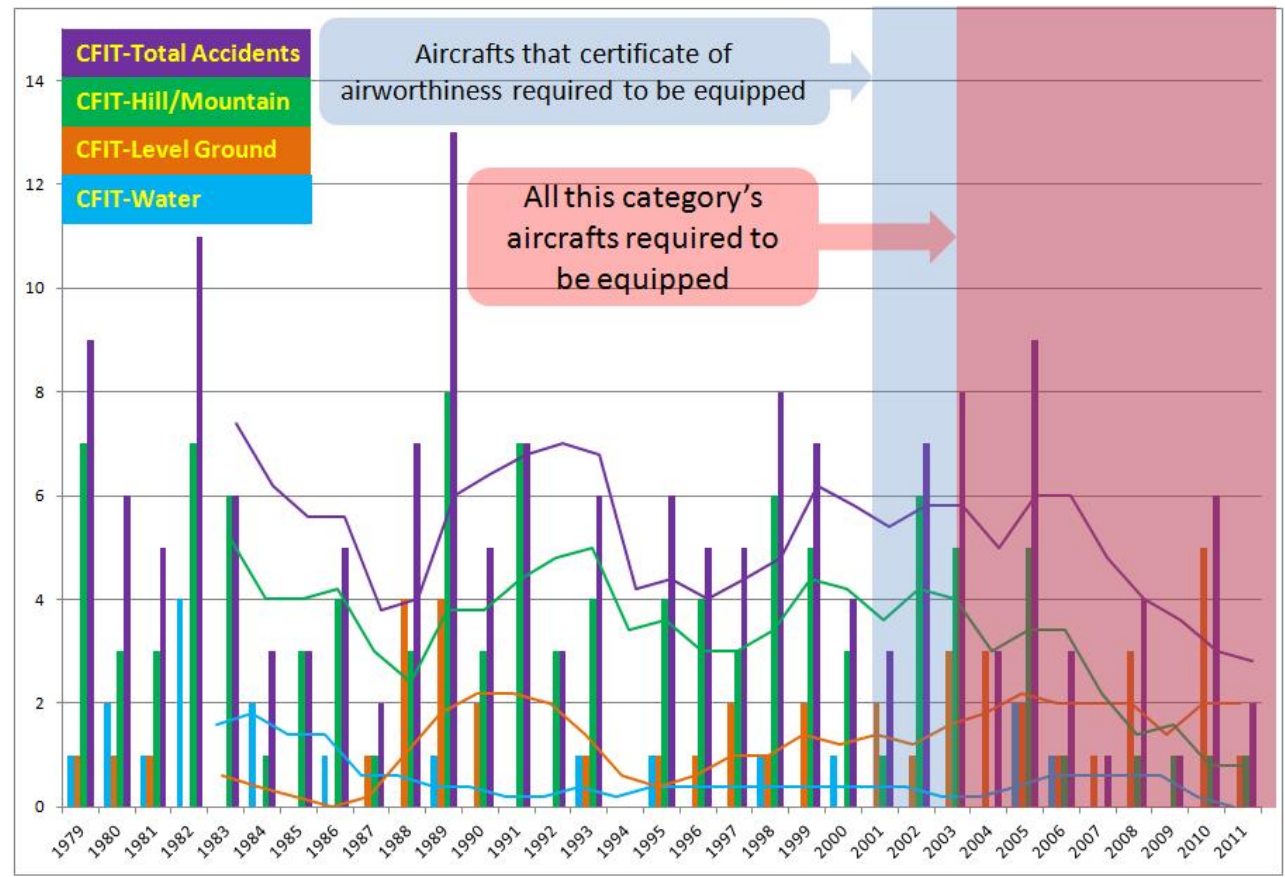

CFIT-Level Ground had a similar pattern with increasingly rising slope in the latter stage, whereas CFIT-Hill/CFIT-Mountain differed greatly because large aircraft trend fluctuated more than that for small aircraft, which clearly increased in the latter stage. The regulations were enforced for large aircrafts before small ones so it is easy to understand why the accidents involving large aircraft 
declined when the regulations were first introduced to cover them. By contrast, the regulations did not cover small aircraft, which explains why their trend continued to rise.

\subsection{Analysis of the Annual Death Tolls from Cfit Accidents}

Figure 6 shows the annual change in the death toll due to CFIT accidents. This figure shows the distribution of the death toll and the number of accidents is quite different. CFIT-Hill/Mountain accidents contributed the most to the death toll. The death tolls attributable to CFIT-Level Ground and CFIT-Water accidents are stable and low, apart from the accident peaks in 1988 and 1989, which makes the death tolls due to CFIT-Level Ground appear to increase rapidly. After 1994, both types returned to low death tolls. From a general view, the average annual death toll due to CFIT accidents in the past 30 years has fluctuated at around 300 persons, while there was no obvious upward trend in the number of accidents. Between 2000 and 2011, the death toll declined, especially in the most recent five years.

Figure 6: Annual Death Tolls and the Five-Year Average

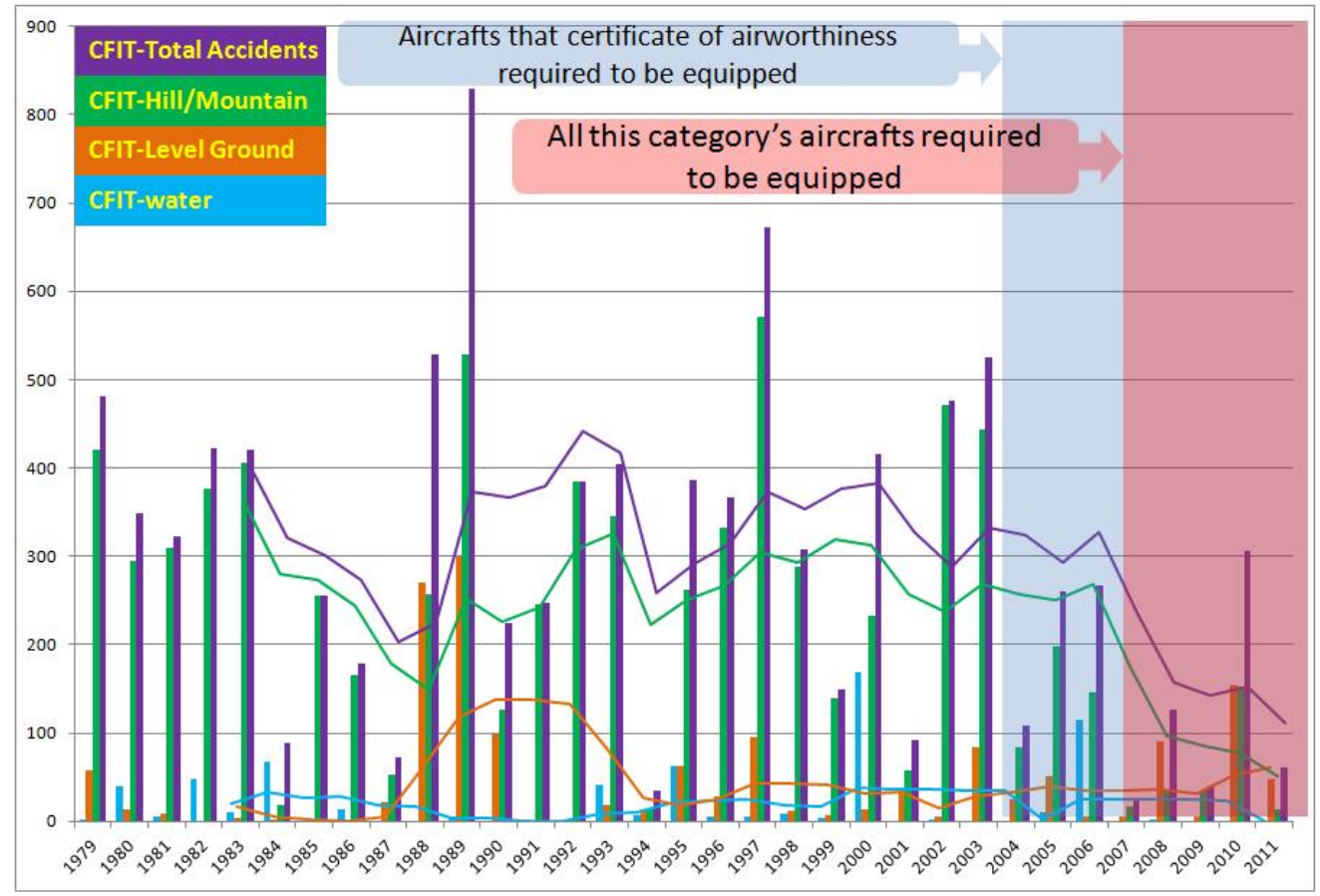

Figure 7 shows the annual death tolls for CFIT accidents involving aircraft with a maximum takeoff weight of more than $5,700 \mathrm{~kg}$ or a capacity of more than 9 people. This figure shows the 
CFIT-Hill/Mountain was still the major cause of death. The numbers have decreased drastically in recent years, but the figures are still high. The death toll attributable to CFIT-Level Ground accidents are generally stable, after excluding the abnormal peaks in 1988 and 1989, and they are similar to the death tolls due to CFIT-Water. The figure also shows that the deaths due to CFIT-Hill/Mountain are higher than those with the other two CFIT types, which is more obvious during 1989 to 1997 and 2002 to 2003, which are attributable mostly to jetliner accidents, including the 1989 deaths of 144 people in Portugal and 127 people in the Republic of Honduras, the 1997 deaths of 288 people in Guam and 234 in Indonesia, the 2002 deaths of 119 people in Iran and 129 in South Korea, and the 2003 deaths of 275 people in Iran. The death toll did not decrease until 2004.

\section{Figure 7: Annual Death Tolls of CFIT Accidents Involving Aircrafts with a Maximum Takeoff Weight of More Than 5,700 Kg or More Than 9 Passengers and the Five-Year Average}

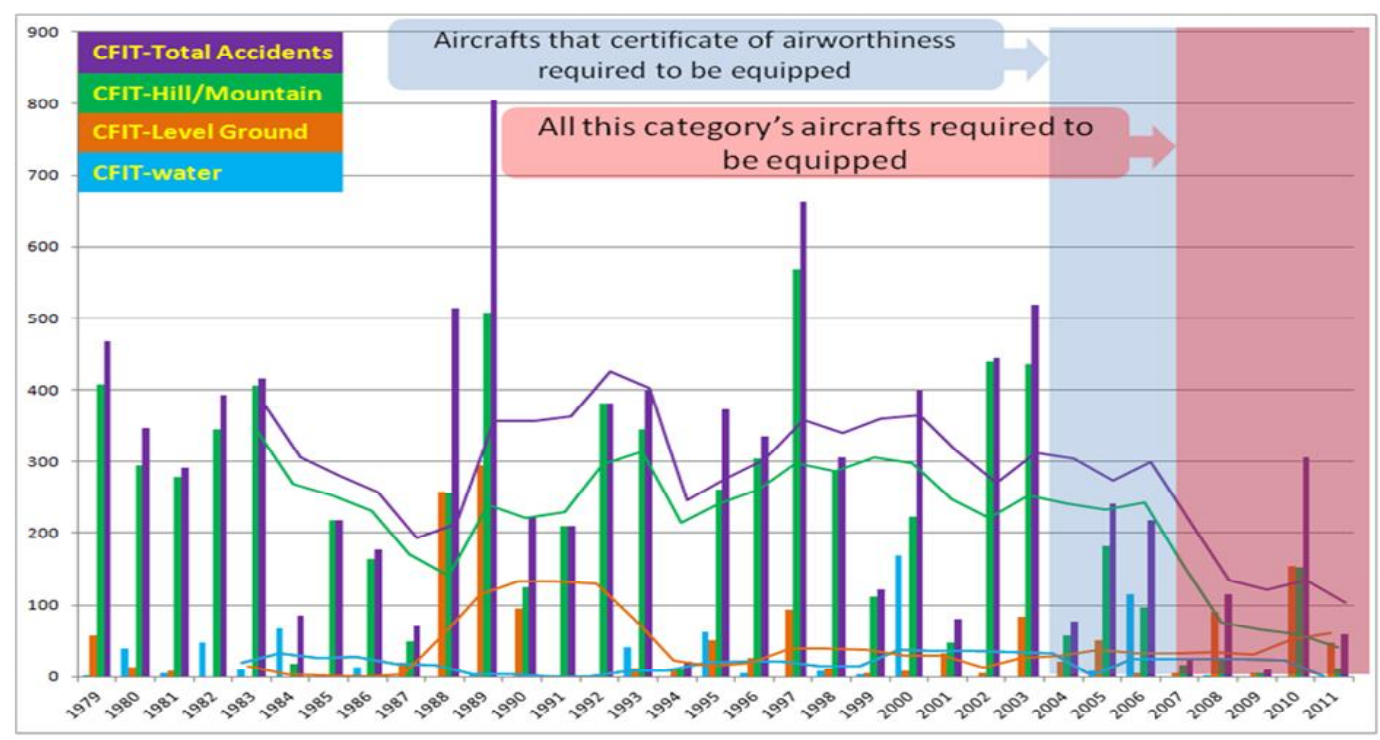

This also demonstrates that the highest death tolls were within less developed regions, i.e., outside the U.S.A., Canada, Europe, and Asia. The CFIT-Level Ground and CFIT-Water accident rates are generally stable, with the exceptions of for the high death tolls due to CFIT- Level Ground accidents between 1988 and 1989 in Indonesia, which claimed 124 fatalities, and in Surinam, which claimed 176 fatalities. The number of accidents remained high in other years but the death toll did not increase. The comparison of aircraft with a maximum takeoff weight of more than $15,000 \mathrm{~kg}$ or a capacity of more than 30 passengers showed that the death rates with large and small aircrafts had 
similar patterns but only the number of accidents increased. In contrast to the obvious differences in the accident trends, it is understandable that small aircraft with fewer passengers have a lower death toll, and the accident rate has risen though.

\subsection{Analysis of the CFIT Death Tolls per Unit Flight}

Given the standardization achieved mandatory GPWS installation and the passenger capacity, this study defined the death toll per unit flight as the test parameter to analyze the death toll during aircraft accidents. When the death toll per unit flight was greater than the regulatory requirement of the passenger carrying capacity, this represented the ineffectiveness of the regulations.

Figure 8 shows the death tolls during CFIT accidents per unit flight and the five-year average distribution. This figure shows the average for CFIT-Water accidents increased by a single event in 2000 that caused 169 deaths. Excluding that event, the average death toll per unit flight was more than 20 passengers. The death toll per unit flight for CFIT-Level Ground accidents, excluding the higher death tolls per unit flight between 1988 and 1990, was even lower than that for CFIT-Water with less than 10 fatalities per unit flight. The CFIT-Hill/Mountain death toll per unit flight was the dominant factor that shaped the overall average and it had a similar to the overall average, with an obvious decline in the most recent 15 years where death toll per unit flight fell from above 40 fatalities to under 10 fatalities. However, the average was still higher than 20 fatalities, which demonstrates that although the regulatory requirement for EGPWS has made some improvements, there is still a long way to go.

The overall average death toll per unit flight has generally remained at less than 40 fatalities and the trend has declined in the last 15 years where that in the most recent seven years was less than 20 fatalities. From a statutory point of view, the death toll per unit flight is higher than 9 fatalities, which was set by the international standard that required GPWS installation, so it is evident that some countries are still substandard and they affect the overall average. 
Figure 8: Death Toll per Unit Flight and the Five-Year Average

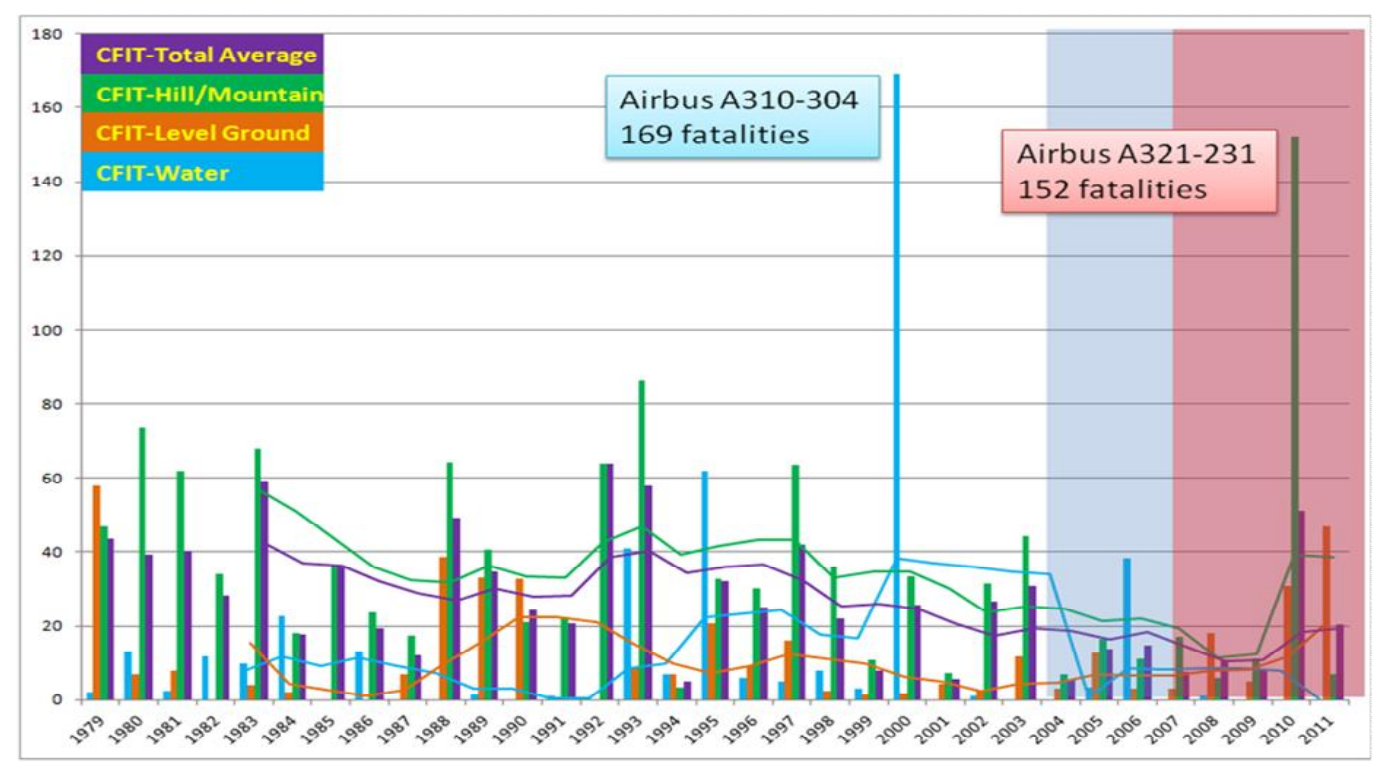

Figure 9 shows the annual death toll per unit flight for CFIT accidents involving aircraft with a maximum takeoff weight of more than $5,700 \mathrm{~kg}$ or a capacity of more than 9 passengers. This figure shows during the last 30 years, CFIT-Hill/Mountain accidents have declined steadily. The ICAO requirement for EGPWS installation in recent years had a major effect on the trend. CFIT-Level Ground accidents have remained low since 1995, and 2002 was the best year, although there was a slight upward trend in the following years, which contradicted expectations. CFIT-Water accidents reached their lowest average level in 1991 but there were many sudden increases, which were attributable mostly to several major CFIT-Water accidents, such as that in 2002, which claimed 169 fatalities, resulting in a soaring five-year average, and it was not until 2005 that it returned to a low level, only to soar again with new accidents.

The death tolls per unit flight in CFIT-Level Ground accidents and CFIT-Water accidents attributable to aircraft with a maximum takeoff weight of $15,000 \mathrm{~kg}$ or a capacity of more than 30 passengers differed little from those after the installation of GPWS in aircraft with a maximum takeoff weight of more than 7,500 kg or a capacity of more than 9 passengers, although the death toll per unit flight in CFIT-Hill/Mountain accidents declined significantly. This implies that although the number of small aircraft flights increased, the death toll did not increased proportionally because of their small size, 
which reduced the average death toll per unit flight. However, this also indicates the necessity of the relevant enactments to cover small aircrafts, so small aircraft should be required to install EGPWS/TAWS and the overall CFIT-Hill/Mountain accidents will be effectively prevented.

Figure 9: Annual Death Toll per Unit Flight for Aircraft with a Maximum Takeoff Weight of More than 5,700 $\mathrm{Kg}$ or More than 9 Passengers and the Five-Year Average

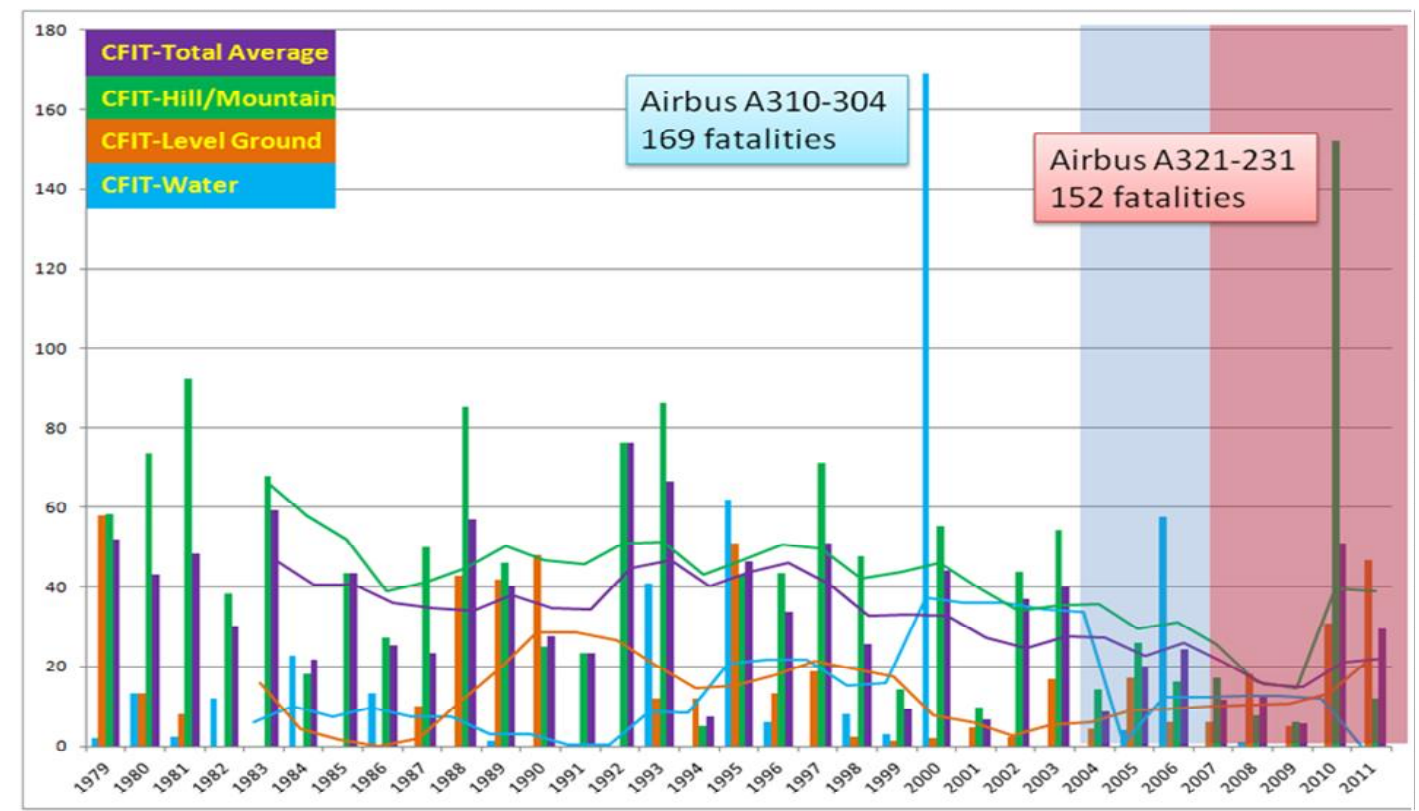

\subsection{Analysis of Geographical Factors Affecting CFIT Accidents By Countries}

This study sampled the U.S.A, Canada, EU, and Asian countries in the comparative analysis. The annual accident rates in these regions were low with about one or two accidents each year, while the annual death tolls were also low. Thus, the death tolls per unit flight converted were low in these regions with an average of about 5 fatalities per unit flight, which satisfies the current enactment that requires aircraft with a capacity of more than 9 passengers to be installed with GPWS/EGPWS/TAWS. However, this is not covered by the current enactment. Two inferences can be made based on an analysis of the geographical aspects. First, future regulations should continue to expand coverage to reduce the CFIT risks of small aircraft (maximum takeoff weight of less than 7,500 kg or a capacity of less than 9 passengers). Second, the analysis showed that although the overall death toll per unit flight was still greater than the regulatory standard, the U.S.A., Canada, EU, 
and Asian countries conformed to the regulations, which shows that the problem lies in other regions. This finding should be the focus of future improvement efforts.

\section{CONCLUSIONS AND RECOMMENDATIONS}

This study analyzed the annual numbers of aircraft accidents, the annual death tolls in these accidents, and the death toll per unit flight accident, as well as geographical factors, and this study reached the following conclusions.

This study defined the death toll per unit flight as the test parameter and this study examined the correlation between CFIT accidents and statutory installation of GPWS. This study compared the death toll per unit flight after this requirement, which showed that the overall frequency of CFIT accidents has been improved. The study result showed that CFIT accidents are mainly CFIT-Hill/CFIT-Mountain and CFIT-Level Ground accidents, which have similar annual trends. The overall trend is based on the distributions of these two CFIT types. Over the last 30 years, the annual average CFIT accident rate before 1995 was less than 10 with little variation. Between 1995 and 2006, however, the number of CFIT accidents increased. After 2007, the overall number of accidents declined dramatically due to the enforced installation of GPWS.

The study shows that there was a significant change in the death toll distribution in recent years and the numbers of accidents. The CFIT-Hill/Mountain accidents had the highest death toll and they dominated the overall distribution. The death toll per unit flight for CFIT-Water accidents was less than 20 people while the overall average death toll per unit flight for CFIT-Level Ground was less than 10 people. The death toll per unit flight for CFIT-Hill/Mountain, being the main factor, had a similar trend with the overall average. There has been a downward trend in the last 15 years, which demonstrates that the installation of GPWS has made improvements, although the death toll per unit flight exceeds nine persons, which shows that some countries are still substandard and such cases have affected the average. 
When this study was extended from larger aircraft with a maximum takeoff weight of more than $15,000 \mathrm{~kg}$ or a capacity of more than 30 passengers to smaller aircraft with a maximum takeoff weight of more than $7,500 \mathrm{~kg}$ or a capacity of more than 9 persons, the death toll per unit flight for CFIT-Level Ground and CFIT-Water accidents did not change much, whereas the death toll per unit flight for CFIT-Hill/Mountain accidents had a significant downward trend. These results demonstrate the necessity for relevant regulations to cover small aircraft and they should be required to be installed with GPWS, so the overall CFIT accident rate can be improved.

The geographical analysis showed that the overall death toll per unit flight was still higher than the statutory standard. However, the U.S.A., Canada, EU, and Asian countries conform to the statutory standard, which indicates that the problem lies in other regions. This finding should focus future efforts in making further improvements in these areas. Finally, this study recommends that future regulations should be more extensive to diminish the CFIT risks for smaller aircraft as well as commercial airplanes.

\section{REFERENCES}

- Amy, R. Pritchett., Balazs, V. and Kimberly, E. (2002), 'Testing and implementing cockpit alerting systems', Reliability Engineering and System Safety, Vol. 75, 193-206 .

- Baxter, G.D. and Ritter, F.E. (1999), 'Towards a classification of state misinterpretation'. In: Harris, D. (ed.) Engineering Psychology and Cognitive Ergonomics, 3, Transportation Systems, Medical Ergonomics and Training. Aldershot: Ashgate, 35-42.

- Billings, C.E. (1997), Aviation Automation. LEA, NJ: Mahwah.

- Boeing (2011), Statistical Summary of Commercial Jet Airplane Accidents Worldwide Operations 1959-2010. Chicago: Boeing Commercial Airplanes Group.

- Dingus, T.A., McGehee, D.V., Manakkal, N., Jahns, S.K., Carney, C. and Hankey, J.M. (1997), 'Human factors field evaluation of automotive headway maintenance/collision warning devices', Hum Fact, Vol. 39, No. 2, pp. 216-29. 
- Elvers, G.C., and Elrif, P. (1997), 'The effects of correlation and response bias in alerted monitor displays', Human Factors: The Journal of the Human Factors and Ergonomics Society, Vol. 39, No. 4 , pp. $570-580$.

- FAA (2000), Installation of Terrain Awareness and Warning System (TAWS) Approved for Part 23 Airplanes. Advisory Circular AC 23-18.

- Learmount, David. (2009), 'Forecasts 2009 - Safety and security are in the doldrums', Flight International, Retrieved 2009-03-19. Available from: http://www.flightglobal.com/news/articles/forecasts-2009-safety-and-security-are-in-the-doldru ms-320871/ (accessed on 7/11/2014).

- Hasse, D. (1992), 'ALPA Ground Proximity Warning System Survey'. In: Proceedings of the Flight Safety Foundation 45th Annual International Air Safety Seminar, Arlington: Flight Safety Foundation, 38-44. Long Beach, Calif., November 2-5.

- Mathews, R. (2004), 'Past, Current and Future Accident Rate: Achieving the Next Breakthrough in accident Rates'. In: ISASI (International Society of air Safety Investigators) 2004 proceeding, Gold Coast, Australia, August 30-September 2.

- Moray, N. (1987), 'Intelligent aids, mental models, and the theory of machines', International Journal of Man-Machine Studies, Vol. 27, No. 5, pp. 619-629.

- Mosier, K. L. and Skitka, U. (1999), 'Human Decision Makers and Automated Decision Aids: Made for Each Other?' In: Parasurman R. and Mouloua M. (eds.) Automation and Human Performance: Theory and Applications. Mahwah, NJ: Lawrence Erlbaum, 201-20.

- Parasurman, R. and Riley, V. (1997), 'Humans and automation: use, misuse, disuse, abuse', Hum Fact, Vol. 39, No. 2, pp. 230-53.

- Orlady, H.W. and Orlady, L.M. (1999), Human Factors in Multi-Crew Flight Operations, Aldershot: Ashgate.

- Riley, V. (1996), 'Operator reliance on automation: theory and data'. In: Parasurman, R. and Mouloua, M, (eds.), Automation and Human Performance: Theory and Applications. Mahwah: Lawrence Erlbaum, pp. 19-36. 
- Rudisill, M. (1995), 'Line pilots' attitudes about and experience with flight deck automation: results of an international survey and proposed guidelines'. In: Jensen, R. and Rakovan, L. (eds.) Proceedings of the 8th International Symposium on Aviation Psychology. Columbus: The Ohio State University, pp. 288-293.

- Sanfourche, J. P. (2001), 'New interactive cockpit fundamentally improves how pilots manage an aircraft's systems and its flight', Air \& Space Europe, Vol. 3, No. 1, pp. 68-70.

- Sherry, L., Polson, P. and Feary, M. (2002), 'Designing user-interfaces in the cockpit: five common design errors and how to avoid them'. In: Proceedings of 2002 SAE World Aviation Congress, Phoenix, AZ.

- Sherry, L., Polson, P. and Feary, M. (2002), Designing User-Interfaces For The Cockpit: Five Common Design Errors And How To Avoid Them(No. 2002-01-2968). Warrendale: SAE Technical Paper.

- Vandor, B. and Pritchett, A.R. (1999), Effects of Displays and Alerts on Subject Reactions to Potential Collisions during Closely Spaced Parallel Approaches, IsyE Report R-99-02, Atlanta: Georgia Institute of Technology. 